\title{
Water-SARS-CoV-2 interaction-based mechanism inhibiting virus attachment to host cells
}

\author{
Valery Shalatonin \\ Department of Bioengineering, University of Washington, Seattle, WA 98195, USA \\ Correspondence: valeryshalatonin@gmail.com or f77manta@uw.edu
}

\begin{abstract}
Many studies showed that the enveloped viruses, including coronaviruses, HIV-1, and influenza inactivate significantly faster in water than the non-enveloped viruses. It looks that there is a certain mechanism controlling this phenomenon. However, the epidemic spread of SARS-CoV-2 indicates that this virus - water interaction mechanism is not effective enough to fully inhibit coronavirus reproduction. We hypothesized that a spatially extended layer of the ordered water molecules, formed around $\mathrm{CoV}$ due to the spike's glycans - surrounding water interaction acts as a buffer inhibiting $\mathrm{CoV}$ motion and its attachment to the host cell receptor. There is experimental evidence that water molecules while interacting with glucans experience the long-range ordering and repulsive forces. Our findings revealed new features that can promote its interaction. It was shown that the glycans and water molecules have the same far ultraviolet (UV) absorbance peak at $\sim 185 \mathrm{~nm}$. This peak is a manifestation of the still little-known physical properties possessed by hydroxyl $(\mathrm{OH})$ groups, including those contained in glycans and water molecules. Many studies show that the carbohydrate hydroxyl groups are a key element in the long-range antifreeze glycoproteins activity which is closely correlated with our issue. To further increase ice inhibition, a sugar-based (usually trehalose) water solution, further slowing down the water dynamics is commonly used. Our experiments with sugar-based compounds dissolved in water showed that in such solutions the UV absorbance at $\sim 185 \mathrm{~nm}$ (activity of the $\mathrm{OH}$ groups) can be essentially increased with respect to the bulk water. The spike's glycans - water long-range interaction, activated due to the dissolved sugar-based compound, creates the glass-like stabilizing hydration layer (like in case of the trehalose) effectively inhibiting the virus - host cell binding. It was shown that the chemical structures of the known compounds with proven inhibition of SARS-CoV-2 entry into host cells agree with our findings. The described approach can be effective against human immunodeficiency viruses, influenza viruses, and possibly other enveloped viruses.
\end{abstract}

Key words: SARS-CoV-2; enveloped viruses; spike's glycans; water; hydroxyl groups; far-UV absorbance peak. 


\section{INTRODUCTION}

The novel severe acute respiratory syndrome coronavirus 2 (SARS-CoV-2) has emerged as a human pathogen, causing fever, severe respiratory diseases, pneumonia, and systemic inflammatory response syndrome, leading to a worldwide sustained pandemic. The coronaviruses (CoVs) are a group of enveloped viruses, 100-160 nm in diameter, spherical, single-stranded RNA with large genome and a unique replication mechanism. They are characterized by club-like spikes (S) that protrude from their surface. The spike glycoproteins are densely coated by heterogeneous $\mathrm{N}$-linked glycans which are vital for proper folding and for modulating accessibility to host proteases [1], [2]. Both SARS-CoV-2 and the original severe acute respiratory syndrome coronavirus (SARS-CoV) enter host cells through an interaction between the spike glycoprotein and the angiotensin converting enzyme 2 (ACE2) receptor. Therefore, the spike glycoprotein is the main target of neutralizing antibodies [1-4]. At present the underlying physical mechanisms responsible for the specific binding of SARS-CoV-2 RBD and ACE2 are not fully understood, which prevents the development of anti-coronavirus drugs and therapies [5-7]. In particular, the interaction of the spike glycoprotein surface with surrounding water molecules in extracellular medium is poorly studied. The protein hydration is fundamental to structural stability of protein because non-aqueous solvents in general denature proteins [6]. It is difficult to explain how the hydrophilic side chains at the binding site can get rid of their hydrogen-bonded water molecules, and then interact with each other during the docking process. The previous and recent studies gave surprising information about coronaviruses interaction with water, especially in comparison with non-enveloped viruses [8-11]. Many reports have focused on the impact of air parameters, mainly temperature, and humidity on the spread of SARS-CoV and SARS-CoV-2. The obtained data provide evidence that activity of coronaviruses may be partially suppressed with temperature and humidity increase [12-15]. It turned out that coronaviruses appear to be inactivated significantly faster in water than non-enveloped human enteric viruses with known waterborne transmission. The enteric viruses are small and naked icosahedral particles with no obvious surface structure. They do not have any spikes, susceptible to water molecules. These viruses are found in ground water more often than other viral types, and they have been abundant in untreated river water. The interesting observations were made for human immunodeficiency viruses (HIV) [8]. Over half of the mass of the trimeric envelope spike in HIV are N-linked glycans, more than in the coronaviruses. It was shown that either free HIVs or cell-associated HIVs exposed to water were 
rapidly inactivated, with a $90 \%$ loss of infectivity within 1 to $2 \mathrm{~h}$ at $25^{\circ} \mathrm{C}$. In comparison, polioviruses (PV-1, nonenveloped viruses) showed no loss of infectivity over $24 \mathrm{~h}$. Coronaviruses reduction was quicker in the filtered tap water. However, in both filtered and unfiltered tap water at $23^{\circ} \mathrm{C}, \mathrm{PV}-1$ survived six times longer than SARS-CoVs [9]. SARS-CoV was detected in hospital wastewater, domestic sewage, and tap water for 2 days at $20^{\circ} \mathrm{C}$ and up to 14 days at $4^{\circ} \mathrm{C}$, thus demonstrating temperature strongly influences viral persistence [10], [11].

The similar effects regarding humidity and temperature have been previously reported in numerous studies of influenza viruses. It is an enveloped virus covered with glycoprotein spikes that are spread over its surface [16-20]. Influenza virus causes seasonal outbreaks in temperate regions, with an increase in disease and mortality in the winter months. Dry air combined with cold temperature is known to enable viral transmission. Model predictions suggested that approximately half of the average seasonal differences in US influenza mortality can be explained by seasonal differences in absolute humidity alone. Temperature modestly influenced influenza mortality as well, although results were less robust [17]. Exposure of mice to low humidity conditions rendered them more susceptible to influenza disease. It was shown that increasing relative humidity from $20 \%$ to $50 \%$ can decrease mortality of mice by nearly $50 \%$, indicating that the effect of low humidity is very strong [18]. An exogenous humidification could serve as a scalable non-pharmaceutical intervention for influenza or other viral outbreaks [20]. While these studies clearly show that environmental conditions affect transmission of influenza virus, the impact of ambient humidity on host response to influenza virus infection and disease outcome remains unclear [18]. The known explanation is based on a suggestion that normal homeostasis of tissue cannot be properly maintained, when the general antivirus function of mucins (highly glycosylated proteins) that are secreted onto our mucosal barriers is perturbed by dry air [21-22]. The above studies show that humidity acts not only as a non-pharmaceutical intervention for influenza but furthermore, in a sense, the surrounding water can be regarded as antiviral against the enveloped viruses [20], [23]. Viral envelope proteins from a variety of human pathogens including SARS, HIV-1, and influenza virus are extensively glycosylated [24], [25]. We hypothesized that the long-range interaction between the extracellular water and spike's glycans can lead to a spatially extended layer of ordered water molecules around CoV. This layer acts as a buffer that inhibits $\mathrm{CoV}$ attachment to the host cell. Glycans (short, branched sequences of sugars) 
tend to be hydrophilic, often do not have rigid structures, and instead have significant freedom of motion in aqueous solution [26].

Many research studies show that water-glycans interactions have specific still unexplained properties related mostly to the existence of the long-range interfacial forces. The glycan antennae of the surface-adsorbed glycoproteins apparently impose an ordering on the water, resulting in a strong repulsive force over some tens of nanometers. When the glycan orientation is modified by chemical means, this long-range repulsion disappears [27]. The long-range propagation of the hydrogen bonding in water imposed by the glycans was found in [28], [29]. When studying the properties of water in aqueous solutions via terahertz $(\mathrm{THz})$ absorption, proteins show a longranged influence on water network dynamics, and even small saccharides influence the dynamics of several hydration layers [30]. At nanometer separations, hydrophilic surfaces and macromolecules experience hydration repulsion and remain separated in water [31]. The much more extended long-range ordering of water (tens of micrometers) contacting with hydrophilic surfaces (EZ water) was described in many studies [32], [33].

Spatially extended ordering of bound water due to the long-range glycans-water dynamics correlates with antifreeze glycoproteins (AFGPs) activity [34]. AFGPs enable the survival of organisms living in subfreezing habitats and serve as preservatives. They are specific proteins that can lower the freezing point of aqueous solutions relative to the melting point. Although their function is known, the underlying long-range mechanism is still unclear [34], [35]. The focus of research is shifted towards the analysis of behavior of the hydration shell around AFGPs and the impact of water-dynamics retardation caused by AFGPs on ice crystal growth [36]. The hydration water seems to adopt a state like that of a glass. It means, the water molecules motion is dependent on that of their near neighbors. By impressing a pseudo glassy character on its hydration sphere, the glycoproteins may suppress crystallization at low temperatures, which might afford freezetolerance [37]. The molecular or other mechanism underlying the long-range interactions remains unclear. It was noted in [38] that "the current understanding of biological hydration does tell us is that the issues are more subtle than is often supposed, because water's biological roles are not easily reduced to a handful of properties that follow self-evidently from its molecular nature, or indeed even from the characteristics of the pure bulk liquid." That problem probably correlates 
with a non-chemical, distant method of communication that glycans (glycoproteins) can use to modify the water molecule's behavior. Among candidate mechanisms, electromagnetic radiation, including infrared and ultraviolet radiation appear to have the most experimental support [39].

The described and other results show that water molecules being near hydrophilic glycoprotein surfaces experience the long-range ordering and repulsive forces. We assume that the hydrogenbonded, glass-like ordered network of water molecules can prevent the cell surface binding to the CoV spike's glycans. Nevertheless, the wide spread of SARS-CoV-2 shows that the described water - glucans interactions mechanism is not effective to fully prevent the spread of CoVs. The activity of coronaviruses can be only partially suppressed with temperature and humidity increase. Therefore, the purpose of our study was to increase the efficiency of the glycans-water interactions to prevent CoVs entry into host cells. We established a distinctive physical characteristic of water which most likely is mainly responsible for the interaction. It was shown that the water hydroxyl $(\mathrm{OH})$ groups have specific properties giving them a key role in interaction between glycoproteins and biomolecules including DNA and RNA. The measurements indicated that pure water has an ultraviolet absorption peak at nearly the same wavelength as glycans have, and this peak relates to the water molecules $\mathrm{OH}$ groups. Small water molecules surrounding the spikes and having nearly the same wavelength of the absorbance peak as the spike's glycans have interfere with $\mathrm{CoV}$ binding to the host cell. It was shown that activity of the water hydroxyl groups can be essentially increased by adding to water the sugar-based and some other compounds containing OH groups.

\section{METHODS AND MATERIALS}

\section{Spectral measurements}

All UV spectral measurements were taken using a dual-beam Cary 5000 UV-Vis-NIR Spectrophotometer $(175-3300 \mathrm{~nm})$ having a photometric accuracy of 0.00025 absorbance units. A series of measurements (treated and controlled water) from $180 \mathrm{~nm}$ to $350 \mathrm{~nm}$ took less than 10 min to complete for $0.4 \mathrm{~nm}$ wavelength intervals. Quartz $1-\mathrm{mL}$ cuvettes with $10 \mathrm{~mm}$ path length were used for all measurements. No lids were used to cover the cuvette. Absorbance does not have special units and was measured in dimensionless absorbance units, or AU. That is a logarithmic ratio between the light intensity before and after the beam of light passes through the sample. A zero/baseline correction was applied to all scans using two matched empty cuvettes. All spectra 
were measured with an empty cuvette used in the reference beam. It should be noted that most studies using UV spectroscopy have been carried out at the wavelengths larger than $190 \mathrm{~nm}$ because commercial UV-Vis spectrophotometers are mostly available only for that region. The main difficulty in obtaining far-UV spectra $(122-200 \mathrm{~nm})$ in the liquid phase of a sample is the strong absorption of oxygen and solvent, including water. We found that the acceptable absorbance and noise level gives the real possibility to obtain meaningful UV spectra beginning from approximately $180 \mathrm{~nm}$. During the measurements, the obtained spectra were sometimes noisy (several pulses were superimposed on a spectrum). In such a case this measurement was being repeated several times (usually not more than two-three times). It is important that every time the basic shape and the absorbance peak wavelength of a spectrum were kept practically the same.

\section{Sample preparation}

The deionized (DI) water used in all experiments was obtained from a Barnstead D3750 Nanopure Diamond purification system, Dubuque, IA (type 1 high-performance liquid chromatography grade, resistivity is $18.2 \mathrm{M} \Omega \cdot \mathrm{cm}$ at $25^{\circ} \mathrm{C}$ ). All experiments were performed under laboratory conditions, at room temperature, $21 \pm 1^{\circ} \mathrm{C}$. The experiments were repeated several times (usually three). Representative results, taken in different time intervals or at different concentrations of water solutions are introduced below. DI water, DI water solutions, and DI water suspensions with ascorbic acid, quercetin, d-ribose, and bromelain were used in the experiments. Additional parameters and details are given in the text.

\section{RESULTS}

\section{Far-UV absorbance peak of water}

To obtain more information about properties of CoVs in water and to explain in more detail the water antiviral effects, we analyzed a common method of water purification using the two-wave ultraviolet (UV) radiation: far-UV $(\lambda \sim 185 \mathrm{~nm})$ and $\mathrm{UV}-\mathrm{C}(\lambda \sim 254 \mathrm{~nm})$ [40]. UV radiation has a lot of support in relation to COVID-19 because of its ability to kill bacteria and inactivate viruses. The SARS-CoV-2 has not yet been specifically tested for its ultraviolet susceptibility but many other tests on related coronaviruses, including the SARS coronavirus, have concluded that they are highly susceptible to ultraviolet inactivation in water, in air, and on surfaces. Virus-laden water droplets and aerosols were usually used in experiments [40-42]. UV radiation at $254 \mathrm{~nm}$ is the 
most germicidal because this is the special wavelength near which nucleic acids maximally absorb UV light (at $\lambda \sim 265 \mathrm{~nm}$ ) [43]. The UV radiation usually emits by electrical discharge of lowpressure mercury vapor lamps. Their large resonance line is $\sim 254 \mathrm{~nm}$. Additionally, a second much weaker emission line at $\sim 185 \mathrm{~nm}$ is produced. Photons of the second line, having higher energy $(\sim 6.7 \mathrm{eV})$, can induce photolysis of water and it, possibly is the main factor for the water purification process [44]. The high far-UV absorption of water due to electronic absorption and Rayleigh scattering limits the possibilities of the $185 \mathrm{~nm}$ radiation to directly destroy bacteria and viruses in water. Nevertheless, it was determined that radiation emitted at $185 \mathrm{~nm}$ leads to the unusually large growth of inactivation rates of some bacteria in water if given suitable transmission distance (direct impact). It was shown, for example, that although only $5 \%$ of the energy of a mercury UV lamp may be attributed to the $185 \mathrm{~nm}$ line, the corresponding increase in inactivation rate of gram-negative bacteria was 40\% [45]. The addition of UV light emitted at $185 \mathrm{~nm}$ to UV light emitted with a peak of $\sim 254 \mathrm{~nm}$ significantly increased cell mortality of $P$. subcapitata [46]. However, the effect was not detectable in T. suecica, indicating greater tolerance in this marine alga compared to the freshwater $P$. subcapitata. It probably means that sea water $(3.5 \%$ solution of sodium chloride) and pure water respond differently to the $185 \mathrm{~nm}$ radiation influence. The reason for the extraordinary influence of the $\sim 185 \mathrm{~nm}$ far-UV radiation remains unclear. Our experiments (provided below) and results obtained in [47] show that the far-UV spectrum of water has an absorption peak near this emission line of a vapor lamp. This peak is shifted when water gets salty [47]. It may help explain the specific antiviral properties of the $185 \mathrm{~nm}$ radiation in water.

\section{Far-UV absorbance peak of DNA and RNA}

The research studies analysis shows that the far-UV range radiation is also a specific one for DNA and RNA. It was found that genome structures have an absorption peak in the range of 185-186 $\mathrm{nm}$ [48-52]. Vacuum-UV circular dichroism (CD) spectroscopy was mainly used for the measurements. CD instruments (known as spectropolarimeters) measure the difference in absorbance between the left and right circularly polarized radiation components. It is significant that positive and negative peaks at the $\mathrm{CD}$ spectra directly correlate with the usual absorption peaks [48]. The exceptionally large positive band at about $185 \mathrm{~nm}$ occurs at the vacuum UV CD spectra of the right-handed double- and single-stranded RNAs [48], [49]. RNA usually meets as a single- 
stranded molecule with a right-handed helical conformation. It was found that the right-handed Aand B- forms of RNA and DNA all have an intense positive CD peak at $186 \mathrm{~nm}$ [50]. The vacuum UV CD bands of the double-stranded $(\mathrm{G} \cdot \mathrm{C})$-containing RNAs, were larger than the measured vacuum UV CD bands of their constituent single-stranded RNAs and were similar in having an exceptionally large positive band at about $185 \mathrm{~nm}$ [51], [52]. The interesting results are introduced in [53]. It was shown in experiments with adenoviruses that UV radiation at the wavelengths of 210 - $240 \mathrm{~nm}$ induces increasing damage to a viral component when the wavelength decreases. It is the surprising change in a viral damage level because nucleic acids maximally absorb UV radiation at $\lambda \sim 265 \mathrm{~nm}$ where they usually have the biggest damaging effect on viruses. We suppose that this phenomenon could be due to the presence of the DNA (RNA) absorbance band at around $185 \mathrm{~nm}$. The smaller the wavelength the closer this band and stronger its influence.

\section{Hydroxyl groups are a cause of the far-UV absorbance peak}

The experimental results described in [54] helped to define a part of DNA (RNA) which is responsible for the appearance of the $185 \mathrm{~nm}$ far-UV absorption peak. Three sugars (glucose, fructose, and sucrose) were chromatographically separated and detected with the far-UVabsorbance detector. They are important carbohydrates, commonly referred to as monosaccharides. The results showed the presence of the absorption peak at around $185 \mathrm{~nm}$ for all sugars [54]. The most important monosaccharides are ribose and its deoxygenated form, deoxyribose. In DNA, the phosphate-sugar backbone contains the deoxyribose, and in RNA it contains the ribose. The chair form of the ribose has a similar pattern as that for the glucose and fructose (Table 1). Therefore, just the ribose (deoxyribose) might be responsible for the peak absorption at the wavelength of $\sim 185 \mathrm{~nm}$. The sugar-phosphate backbone where ribose (deoxyribose) holds the DNA together, allows it to dissolve in water, and is used by cells for specific functions. The far-UV-absorption spectra of two types of peptides (diglycine and triglycine) were measured in [55]. The curves of the spectra resemble those reported in [54]. The peak observed at around $185 \mathrm{~nm}$ is attributed into an almost additive absorption by the carboxylic acid functional group $(-\mathrm{COOH})$ [55]. Comparing the structures of the ribose and the carboxylic acid group (Table 1 , compounds 3,4 ) it can be concluded that the examined absorption peak at $\lambda$ $\sim 185 \mathrm{~nm}$ most likely is a hydroxyl $(\mathrm{OH})$ group property. 


\section{Far-UV absorption properties of the SARS-CoV-2 spike glycoprotein}

In comparison with SARS-CoV-2 (100-160 nm in diameter) water molecules $(\sim 0.28 \mathrm{~nm}$ in diameter) are much smaller. Previous and new studies of SARS-CoV and SARS-CoV-2 spike glycoprotein structures showed that coronavirus $\mathrm{S}$ glycoproteins are densely decorated by heterogeneous $\mathrm{N}$-linked glycans protruding from the trimer surface [1]. Glycan is any chain-like polysaccharide composed of single sugar molecules, containing hydroxyl groups. They are the primary functional group that is found in organic compounds, including sugars. It means that the SARS-CoV-2 spike glycoprotein structures (glycans) have the same far-UV absorption peak as water and other compounds containing hydroxyl groups. Water shell of the genetic material is also of great relevance to the natural biological functions of DNA and RNA. The sugar-phosphate backbone of RNA contains an $\mathrm{OH}$ group attached to the 2 ' carbon atom of the ribose ring. This hydroxyl group which is absent in DNA strongly affects the hydration pattern at the RNA surface. The 2 '-OH groups induce a regular and well-defined hydration pattern in the minor groove of the RNA helix. X-ray diffraction studies and molecular dynamics simulations have suggested that the first hydration layer around RNA contains a somewhat larger number of water molecules in a more ordered arrangement, compared to DNA [56]. These findings show that the hydroxyl groups can interact with the bound water sheath, and their joint impact is likely more effective.

\section{Far-UV absorbance spectra of water}

As mentioned previously, our measurements of the far-UV absorbance spectra of water show the presence of the absorbance peak at $\sim 185.8 \mathrm{~nm}$. The measured spectra for three types of water are given in Figure 1. It is seen that the absorbance peak wavelength of the waters is a little bigger, than the value of the same parameter $(\lambda \sim 185 \mathrm{~nm})$ measured in [54], [55]. This is most likely because water molecules contain specific hydroxyl groups: covalent bonds are formed by two hydrogen atoms attached to the sides of a single oxygen atom. The little shift in the absorbance peak wavelength is not important for the purpose of this research, so its emergence is not analyzed here in detail. It was found in [47] that the absorption peak has a gradual blueshift, getting wider, and bigger as the concentration of a substance without hydroxyl groups $(\mathrm{NaCl}, \mathrm{KCl})$ increases. It means that sea water (3.5\% solution of sodium chloride) and pure water can have different influences on CoVs activity [46]. 


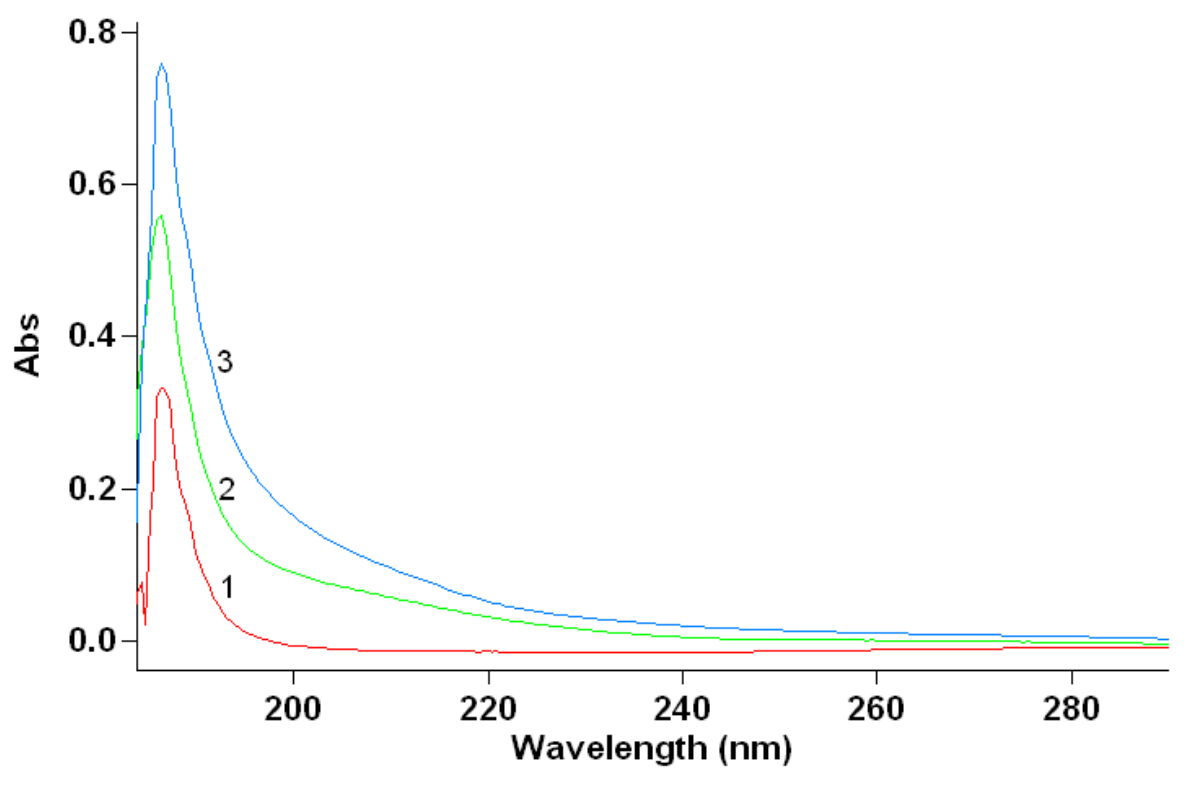

Figure 1. UV absorption spectra of different types of water: 1 - DI water, 2 - rainy water, 3 - tap water. They have the same UV absorbance peak at the wavelength of $\sim 185.8 \mathrm{~nm}$.

\section{Far-UV absorption spectra of ascorbic acid (AA)}

Ascorbic acid is a natural water-soluble vitamin (vitamin C). Its chemical structure is given in Table 1. The AA acts as an antioxidant and has lots of other useful properties. The AA powder was dissolved in DI water and UV spectra of the resulting solutions were measured (Figure 2). It is seen that there is a sharp absorption peak at $\sim 185.8 \mathrm{~nm}$ and an absorption region between $\sim$ $215 \mathrm{~nm}$ and $~ 300 \mathrm{~nm}$. There is a good consistency between the obtained UV absorption spectra (Figure 2) and UV absorption spectra given in [57] for wavelengths bigger than $200 \mathrm{~nm}$ (no data seems to exist for $\lambda<200 \mathrm{~nm}$ ). It was concluded in [48] that "AA absorbs between 210 and 290 $\mathrm{nm}$ with a maximum at $\sim 247 \mathrm{~nm}$ for concentrated aqueous solutions." The absorption of the solution gets bigger as the concentration of AA increases. At the same time, the wavelength of the peak and its sharpness does not change. On the contrary, the absorption band shows a trend toward its increase. One more interesting feature. The UV absorption values of the AA solutions including the $185.8 \mathrm{~nm}$ peak (Figure 2) are mostly bigger in comparison with the water samples spectra (Figure 1). It looks like that hydroxyl groups in the dissolved ascorbic acid are more active. They absorb $6.67 \mathrm{eV}$ photons $(\lambda \sim 185.8 \mathrm{~nm})$ much better and possibly activate usually not-so-active water hydroxyl groups. 


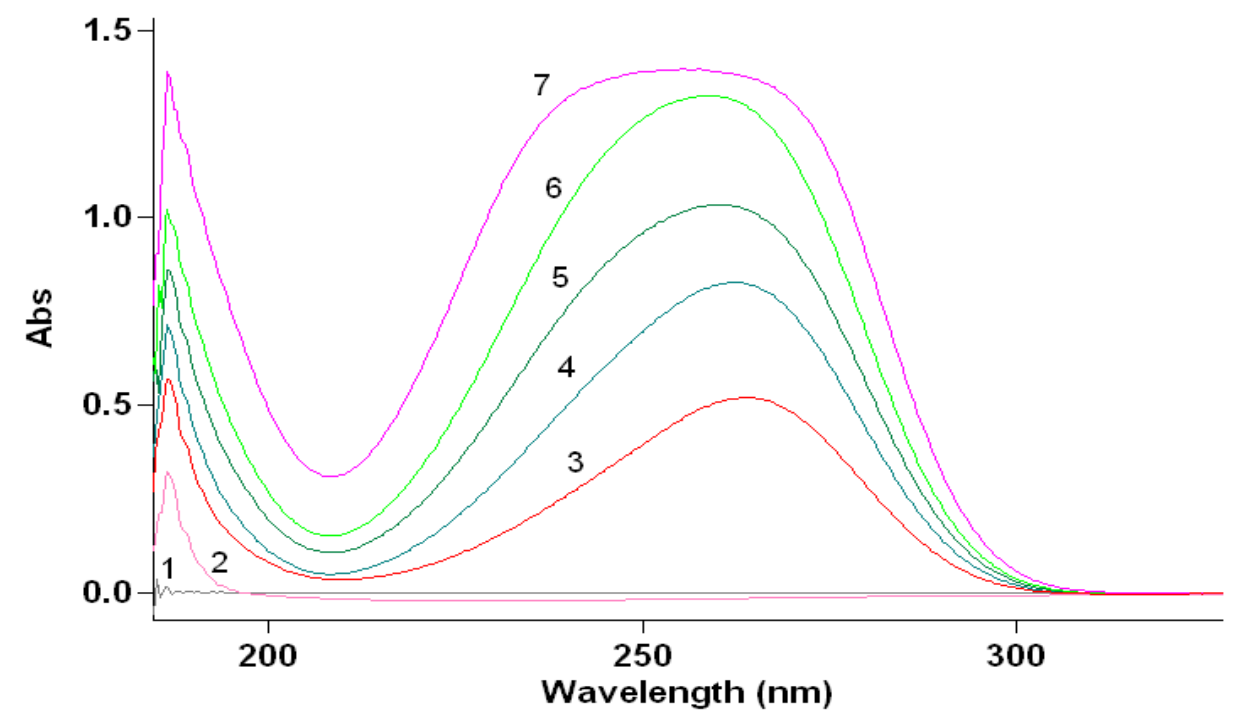

Figure 2. The UV absorption spectra of the ascorbic acid dissolved in DI water: 7 - $14 \mathrm{mg} / 100$ $\mathrm{mL} ; 6$ - $9 \mathrm{mg} / 100 \mathrm{~mL} ; 5$ - $7 \mathrm{mg} / 100 \mathrm{~mL} ; 4-5 \mathrm{mg} / 100 \mathrm{~mL} ; 3$ - $3 \mathrm{mg} / 100 \mathrm{~mL} ; 2$ - DI water; 1 two empty cuvettes.

\section{Far-UV absorption spectra of D-ribose}

D-ribose is a component of the ribonucleotides from which RNA is built. It is a polar compound that readily dissolves in water. The number of primary and secondary hydroxyl groups in ribose (five-carbon sugar) are one and three respectively (Table 1). In addition to its role in RNA, ribose is critical to the production of ATP (adenosine triphosphate). The D-ribose powder was dissolved in DI water and UV spectra of the resulting solutions were obtained (Figure 3). The peak absorbance value is being increased as the D-ribose concentration increases. The far-UV spectra shapes (curves 2, 3, and 4) practically repeated the shape of DI water far-UV spectrum (curve 1). The peak absorption wavelength $(\lambda \sim 185.8 \mathrm{~nm})$ remained the same in all cases. It is not a surprising result because the molecular structure of D-ribose consists mostly of the hydroxyl groups which like in case of the ascorbic acid have the bigger absorbance (activity) than in water molecules. 


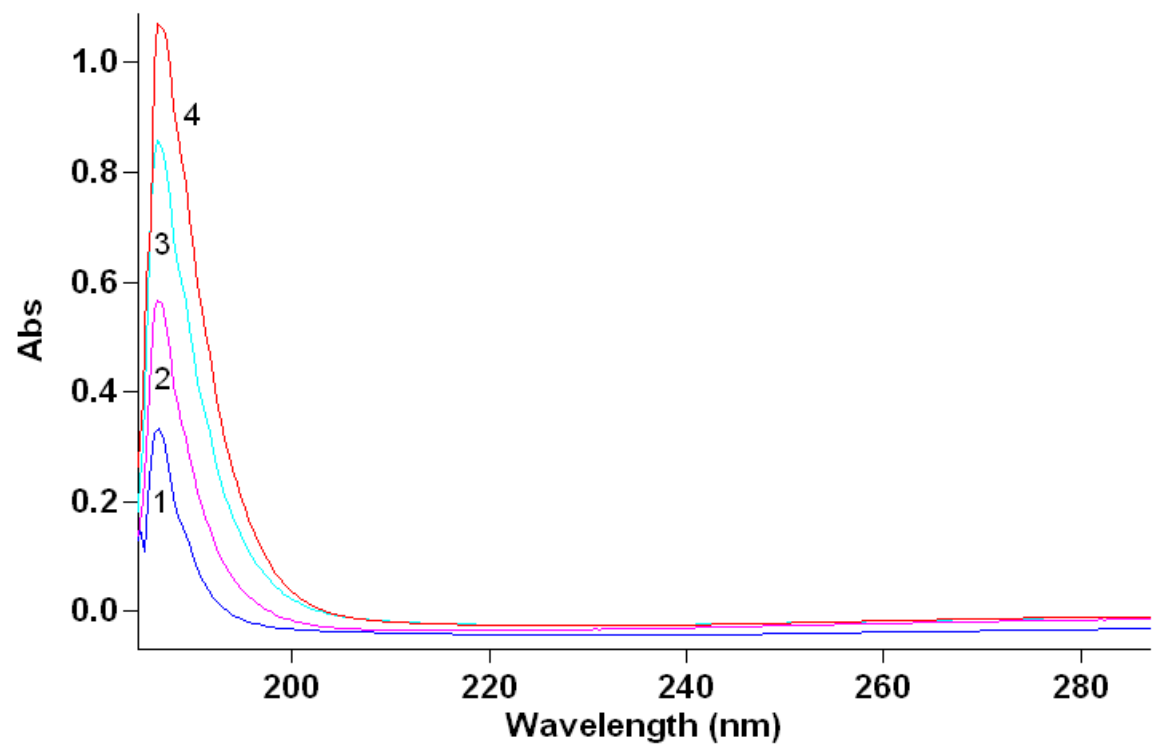

Figure 3. The far-UV absorption spectra of the D-ribose dissolved in DI water: 1- DI water, 2 $12 \mathrm{mg} / 100 \mathrm{~mL}, 3-30 \mathrm{mg} / 100 \mathrm{~mL}, 4-50 \mathrm{mg} / 100 \mathrm{~mL}$.

\section{CoV survival in filtered and unfiltered tap water}

It was found that SARS - CoV inactivation was faster in filtered tap water than unfiltered tap water [9], [10]. Virus survival was determined in both unfiltered tap water and tap water passed through the $0.2-\mu \mathrm{m}$ pore size filter to remove bacteria. For poliovirus (PV-1) which is composed of an RNA genome and a protein capsid, however, filtration made little difference in its survival in tap water. Our findings can explain this phenomenon but only if the cellulose-based filters were used. We showed experimentally that water when passed through the cellulose-based filter can increase its far-UV absorbance. Cellulose is a linear organic polysaccharide composed of many glucose monosaccharides. It is also essential that cellulose is a hydrophilic substance insoluble in water. Its thousands of linked glucose molecules have lots of $\mathrm{OH}$ groups creating the far-UV absorption peak (Table 1). Based on the preponderance of the hydroxyl groups, cellulose polymer is very reactive with water. Water molecular smallness promotes the reaction with the cellulose chains and immediately forms hydrogen bonds [58]. Therefore, the properties of water passed through the cellulose-based filters can be changed, especially at the far-UV absorbance peak region which is directly related to $\mathrm{OH}$ groups. Such water interacts more strongly with CoVs spikes, susceptible to water molecules and it can lower the CoVs survival. We suppose that it happened with the 
filtered tap water [9]. To see whether the filtered water changed its far-UV absorption spectrum, we tested $100 \%$ cotton, which consists of about $95 \%$ cellulose. A flat piece of cotton $(4.5 \mathrm{~cm} \times 3$ $\mathrm{cm})$ was gently placed into a glass petri dish $(50 \mathrm{~mm}$ inside diameter $)$ with $10 \mathrm{~mL}$ of DI water (Figure 4). The same amount of DI water (control water) was poured into another petri dish (PD)

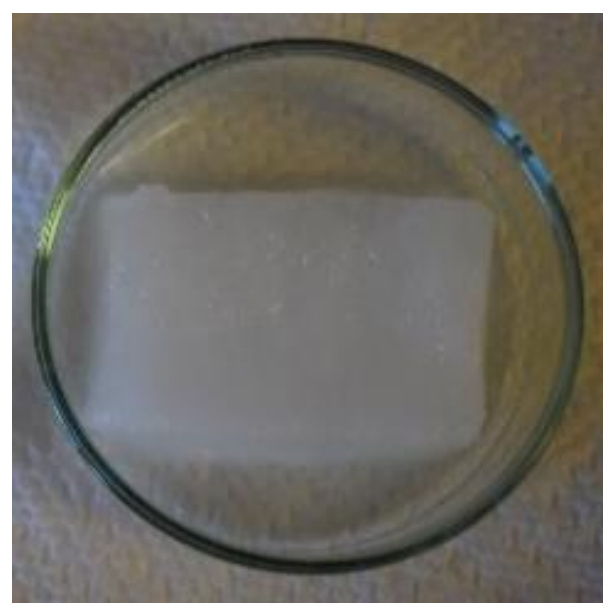

Figure 4. The water-soaked peace of cotton in the petri dish

placed near the PD with the piece of cotton. The far-UV spectra of the cotton-treated and control water were measured in different time intervals after the experiment had started. Cotton is a good absorber of water, therefore in $15 \mathrm{~min}$ it absorbed practically all the water. Therefore, to have a water sample for measurement $(1 \mathrm{~mL})$ we had to softly press the cotton surface. The water samples were taken from the edge of the PD at the maximum distance from the cotton. The far-UV absorption spectra of the control and cotton-treated DI water are shown in Figure 5. The cotton surface was pressed to obtain the water samples in 30 and $45 \mathrm{~min}$ after the beginning of the experiment (curves 3 and 4). The control water far-UV spectra have been changed to a slight extent. The treatment produced the significant growth of the absorbance by approximately 0.7AU. The fifth water sample which was taken in 90 min gave practically the same far-UV spectrum (not shown) as for the previous water sample (curve 4). It is not surprising that growth of the absorbance is limited. 


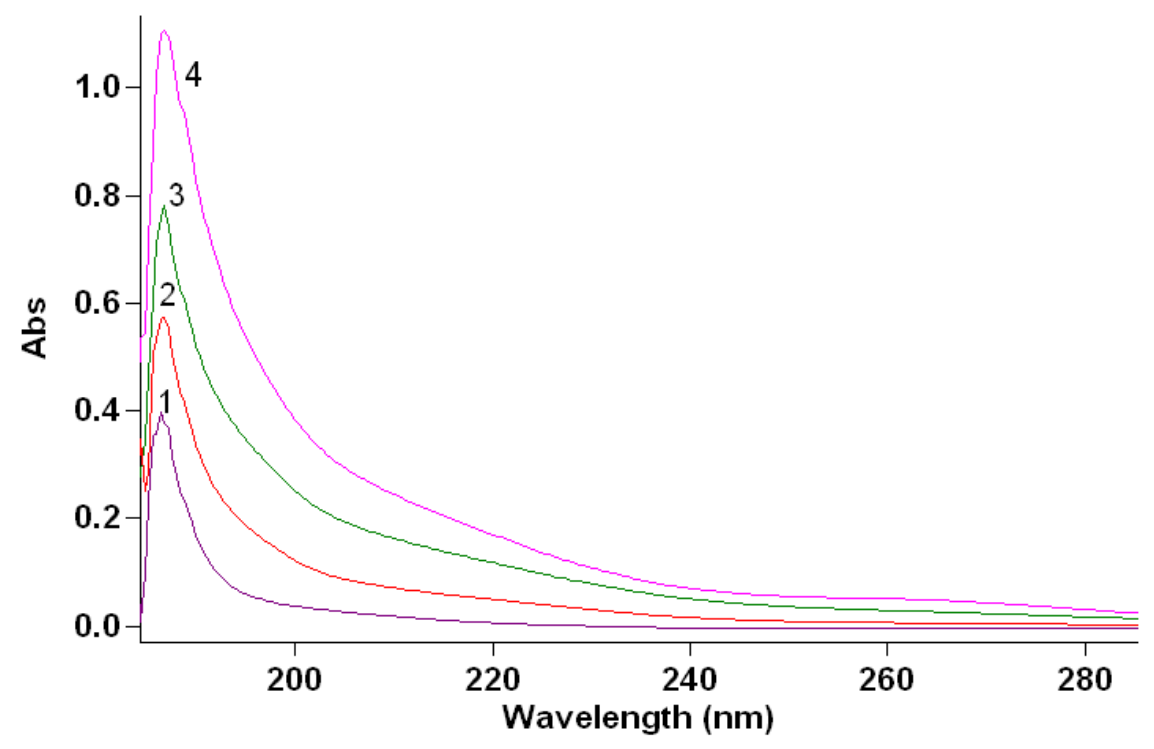

Figure 5. The UV absorption spectra of the control and cotton-treated DI water: 1 - DI water, 2 $-15 \min , 3$ - $30 \mathrm{~min}, 4-45 \min$.

\section{Far-UV absorption spectra of quercetin}

Quercetin (originally labeled vitamin P) is a well-known flavonoid whose antiviral properties have been investigated in numerous studies. The quercetin has been found in laboratory studies to inhibit a wide variety of viruses, including SARS-CoV. It was shown that quercetin can antagonize SARS-CoV entry into target cells [59]. It is consistent with our approach because quercetin, as a plant flavonol has two hydroxylated benzene rings in its structure (Table 1, compound 7). Like cotton, quercetin is insoluble in cold water, and in powdered form was obtained from Samsara Herbs Inc. To test the possible influence of the quercetin on water far-UV spectrum, we added some amount of the powdered quercetin and DI water into a vessel, then covered it and gently shook for half a minute. To have control water, the second vessel with DI water was similarly shaken. Before measurement, to precipitate the quercetin suspended particles, these two vessels were put in a dark place for three hours. Then, the UV absorption spectra of the prepared samples were measured (Figure 6). It is seen that the water treated by quercetin $(50 \mathrm{mg} / 100 \mathrm{~mL})$ has the absorption peak at $\sim 185.8 \mathrm{~nm}$, and it is higher than the same peak in the control DI water. The increase of the absorption was also observed in our experiment with the cotton. It means that water increases its hydroxyl groups activity when contacts with insoluble compounds containing 
hydroxyl groups (cotton and quercetin in our experiments). This phenomenon needs to be studied in more detail.

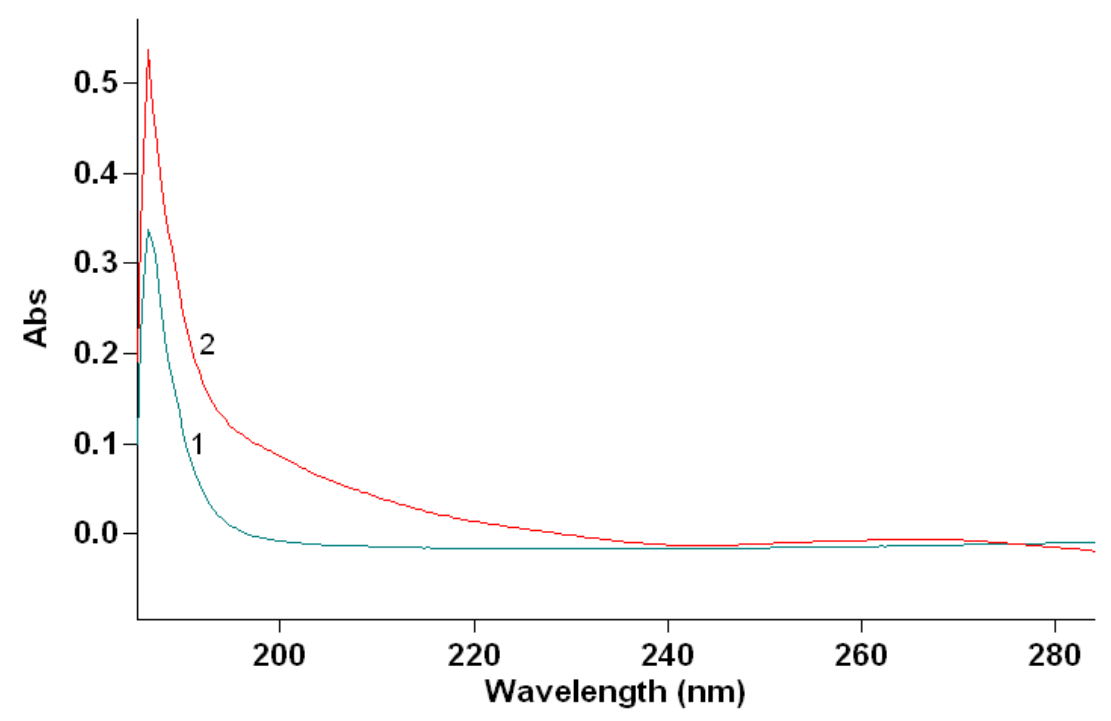

Figure 6. The far-UV absorption spectra of the quercetin: 1- DI water, 2 - DI water with suspended powder of quercetin $(50 \mathrm{mg} / 100 \mathrm{~mL})$ which was saved for three hours to precipitate the quercetin suspended particles.

It was recently shown that quercetin in combination with vitamin $\mathrm{C}$ have synergistic effects and can be used against SARS-CoV-2 [60]. Their chemical structures (Table 1, compounds 5, 7) and our experimental results confirm such a possibility.

\section{Chemical structures of the antiviral compounds}

To check how our findings correlate with the known compounds for COVID-19 treatment, several of them have been analyzed briefly. We directed attention to Chloroquine, Emodin, $\beta$-D-N4Hydroxycytidine (NHC), bromelain, luteolin [61-66], and tetra-O-galloyl- $\beta$-d-glucose (TGG) [59]. Chloroquine. This drug does not contain hydroxyl groups (Table 1, compound 10) and from our point of view (interaction with the surrounding water) cannot be used as an inhibitor of the coronavirus's spike activity. It was shown recently that chloroquine does not inhibit infection of human lung cells with the SARS-CoV-2 [61].

Emodin is a natural anthraquinone derivative that occurs in many widely used medicinal herbs. It was shown that emodin blocks the SARS coronavirus spike protein [62]. This data correlates with 
the emodin structure containing hydroxyl groups (Table 1, compound 9). However, emodin could lead to hepatotoxicity, kidney toxicity, and reproductive toxicity [63]. Probably, this is a reason why this drug is not used in COVID-19 treatment.

NHC. The widely known NHC (Table 1, compound 8) is a bioavailable ribonucleoside analog that has been shown to have broad-spectrum antiviral activity against various viruses including CoVs and is a promising candidate for future clinical development [64], [65]. The NHC structure contains a ribose ring, which hydroxyl groups can promote antiviral activity against CoVs.

Bromelain. Bromelain belongs to thiol proteases, and is a proteolytic enzyme extracted from pineapple, mainly found in the stems and in fruits. It is a glycoprotein with an oligosaccharide in its molecular structure. It was shown recently that bromelain inhibits SARS-CoV-2 infection in VeroE6 Cells [66]. It seems that our findings are consistent with these results. The OH groups which are in the molecular structure of bromelain define its reactivity, including the abovedescribed interaction (Table 1, compound 11). To test the possible influence of the bromelain on the water UV spectrum, bromelain powder was dissolved in DI water and far-UV spectra of the resulting solutions were measured (Figure 7). It is seen that there is a sharp and stable absorption

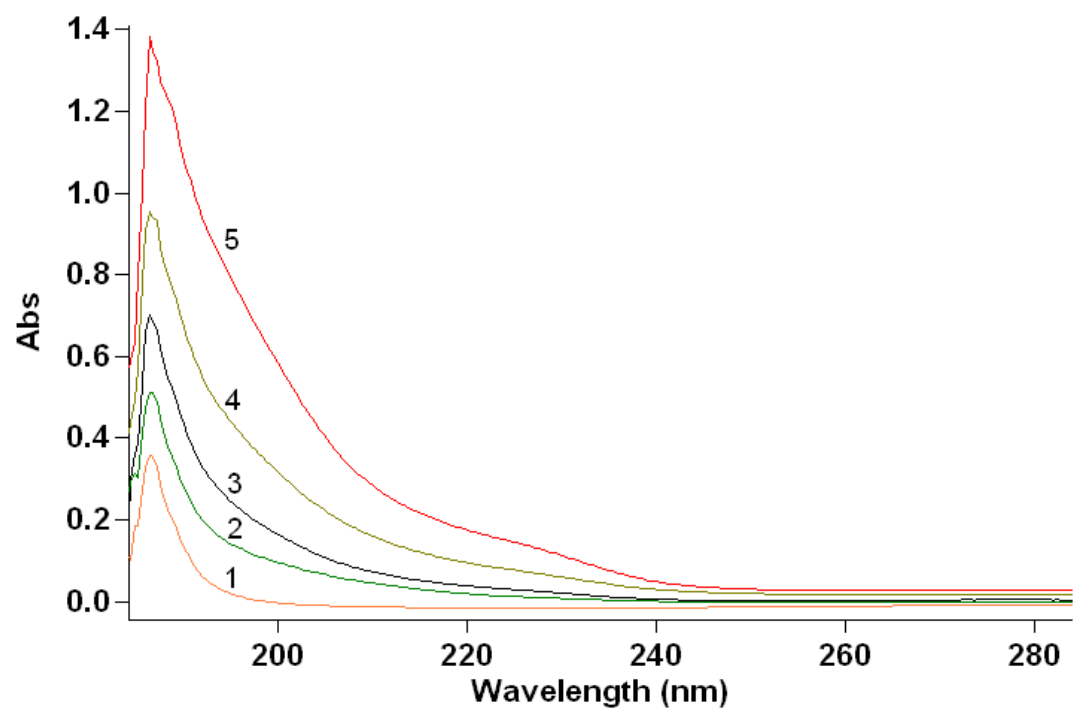

Figure 7. The far-UV absorption spectra of the bromelain dissolved in DI water: 1- DI water; 2 12.5mg/100mL; 3 - 50mg/100mL; 4 - 100mg/100mL; 5 - 200mg/100mL. 
peak at $\sim 185.8 \mathrm{~nm}$. The peak absorbance value is being increased as the bromelain concentration increases. According to our findings, a big number of hydroxyl groups in the bromelain molecular structure create much larger absorption peak at $\lambda \sim 185 \mathrm{~nm}$ in water molecules surrounding $\mathrm{CoV}$ and that in turn leads to the inhibition of the virus entry into the target cell.

Luteolin and Tetra-O-galloyl- $\beta$-d-glucose (TGG). These two small molecules were identified from extracts of 121 Chinese herbs [59]. They appear to be highly effective in inhibiting the entry of both wild-typed SARS-CoV and HIV-luc/SARS pseudotyped virus into Vero E6 cells. It was also noted that the detailed mechanism by which TGG and luteolin exert anti-SARS-CoV activity has not been established. As is shown in Table1 (compounds 12,13) these two compounds contain mostly hydroxyl groups and therefore tend to dissolve in water. The properties of functional groups play a significant role in the characteristic chemical behavior of individual compounds incorporating these specific groups. It means that just the $\mathrm{OH}$ groups specific properties define the reactivity of these compounds including their antiviral activity. The TGG chemical structure and antiviral properties are fully in agreement with our approach.

Table 1. Chemical structures of the selected compounds

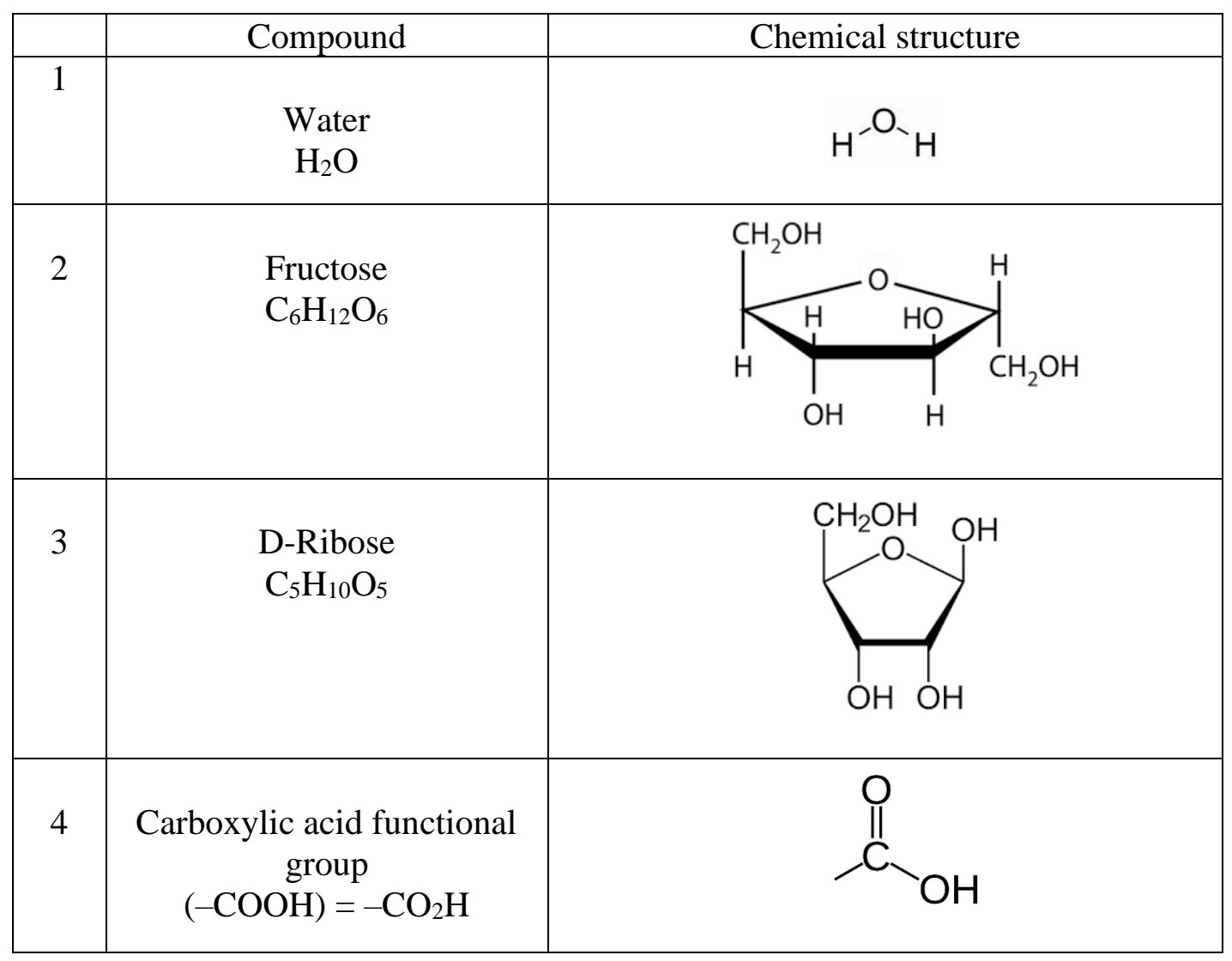




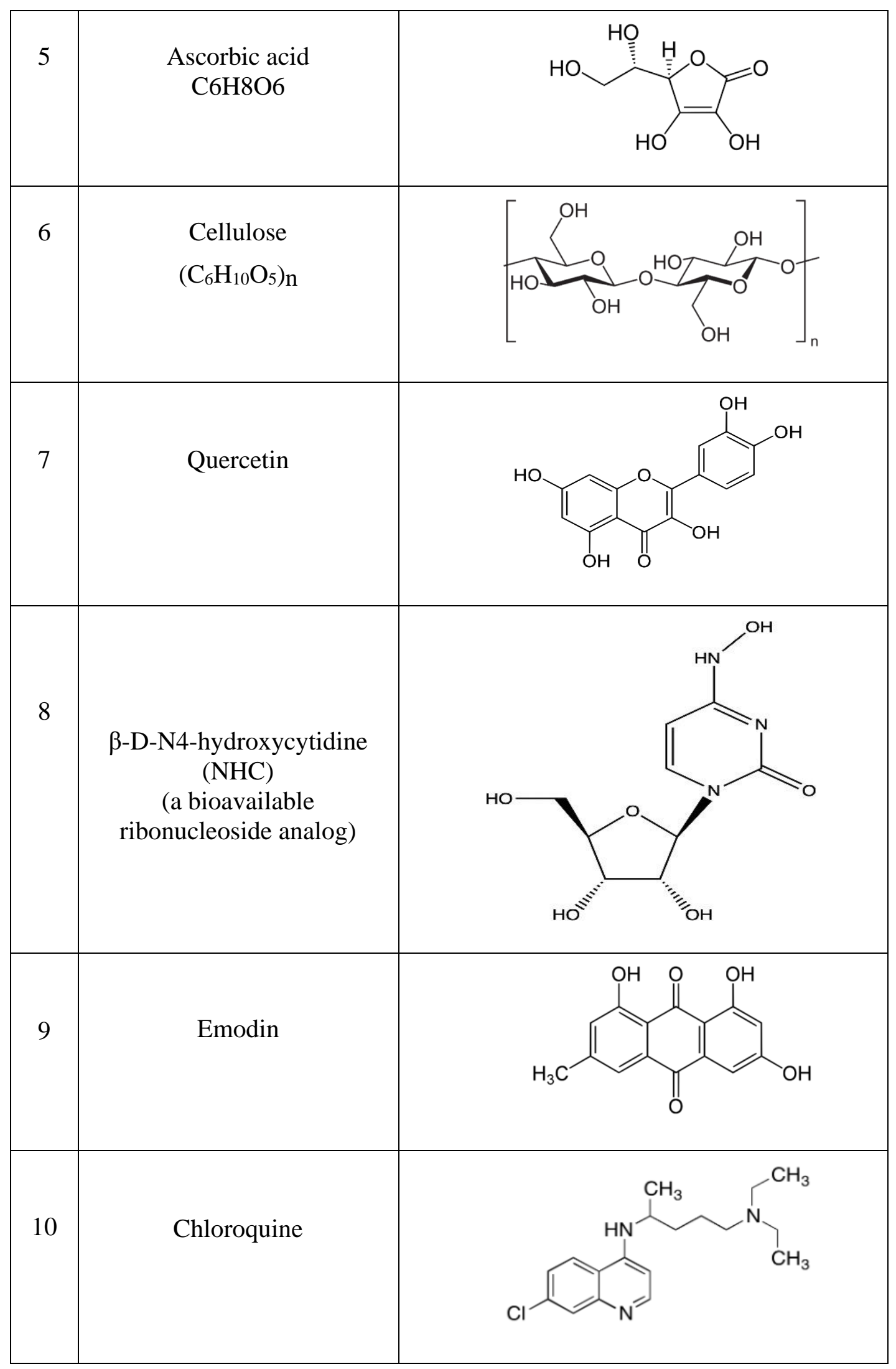




112 Luteolin

\section{CONCLUSIONS AND DISCUSSION}

Many studies showed that coronaviruses are rapidly inactivated in water. The other enveloped viruses, such as HIV-1 and influenza also appear to be inactivated significantly faster in water than the non-enveloped viruses with known waterborne transmission. The seasonal increase of the 
temperature and relative humidity can only partially suppress the coronavirus infection. It looks that there is a certain mechanism controlling this phenomenon. In this study we have tried to reveal this mechanism and to find the possibility to further inhibit the CoVs activity. Most enveloped viruses are extensively glycosylated by a shell of heterogeneous oligosaccharides. There are experimental results showing that the water molecules being near glycans can experience the longrange ordering and repulsive forces. The underlying precise mechanism of this complex interaction is still not fully understood. It was suggested that the ordered layer of the water molecules under certain conditions can act as a buffer that inhibits coronavirus mobility and attachment to the host cell. The wide spread of SARS-CoV-2 shows that the intrinsic spike's glycans - water interactions cannot fully inhibit CoVs attachment to the host cells. Our findings revealed new features that can promote this interaction. It has been shown experimentally that water (tap, distilled, DI) has the peak (maximum) value of absorbance at the wavelength of $\sim 185 \mathrm{~nm}$, and this is a manifestation of the little-known properties possessed by hydroxyl $(\mathrm{OH})$ groups in the far-UV region. Hydroxyl groups are the primary functional group that is found in organic compounds, such as sugars. Therefore, the far-UV spectra of the glycans (polysaccharides) also have the same absorbance peak. Several scientific studies have shown that DNA and RNA also have the far-UV absorption peak at nearly the same wavelength as water and glucans have. It is assumed that the reason of this peak are the hydroxyl groups containing in its pentose sugars.

It is well-established that the carbohydrate hydroxyl groups are a key element in the long-range antifreeze glycoproteins (AFGPs) activity mechanism, which is closely correlated with the longrange glycan-water interactions and studied much better [34]. To further increase the AFGPs ice recrystallization inhibition, a sugar-based water solution is commonly used (mostly on the base of the disaccharide trehalose). The known hypothesis links the efficiency of its protective role to strong modifications of the tetrahedral arrangement of water molecules in the sugar hydration shell. Sugars may strongly slow down protein dynamics by forming hydrogen bonds with the protein hydration water molecules [67], [68]. The neutron scattering and modeling of a proteinwater - trehalose interaction show that the proteins are preferentially hydrated, and analysis of the dynamical properties show that the protein residues are slowed down because of reduced dynamics of the protein hydration shell, rather than because of direct trehalose - protein interactions [69]. These features can be explained that the trehalose, like other sugar-based compounds, increases 
the water $\mathrm{OH}$ groups peak absorbance (i.e., its activity) at the wavelength of $\sim 185 \mathrm{~nm}$. That increases the activated water - AFGPs long-range interaction and "further suppresses crystallization of the solvent when the intrinsic "glassiness" of hydration water is not sufficient" [37]. The appearance of a very slow, glass-like water dynamics decreases the protein motions [70]. The long-range ordering interaction of the spike's glycans with the activated surrounding water is like the AFGPs long-range interaction with the trehalose aqueous solution. Such spike's glycans - water interactions, activated by the dissolved sugar-based compound, creates the glass-like stabilizing hydration layer that in comparison with the ordinary water can inhibit the virus - host cell binding much more effectively. Our experiments showed that adding the sugar-based or some other $\mathrm{OH}$-containing compounds to water can essentially increase the peak absorbance with respect to the bulk water. It has been demonstrated for some water soluble (ascorbic acid, d-ribose, and bromelain) and insoluble (cellulose, quercetin) compounds.

The important function of the hydroxyl groups in AFGPs activity was established still many years ago. It was concluded in [71] that the functional groups responsible for the activity appear to be the hydroxyl groups of the carbohydrate side chains. The synthesis of the synthetic analogues of AFGPs also showed that the $\mathrm{OH}$ groups are an important part in the mechanism of their action [72]. Remarkably, polyvinyl alcohol (PVA) containing primarily $\mathrm{OH}$ groups (Table 1, compound 14), displays some of the same cryoprotective properties as many antifreeze proteins found in cold tolerant organisms [73]. Although it lacks the complex polypeptide backbone of most AFGPs, PVA is like AFGPs in that it contains the $\mathrm{OH}$ groups, which have been found to be a key element in the ice recrystallization inhibition effect of PVA [74]. A study [75] suggests that the concentration of hydroxyl groups is the relevant parameter, guiding both water-sugar and sugarsugar interactions, and no specific effect of trehalose was detected that could provide an explanation for the better bioprotective features of this disaccharide. It means that the long-range slowing down of water dynamics probably can be achieved by increasing the number of $\mathrm{OH}$ groups in aqueous solutions or (and) its activity. It looks that the essential increase of the water OH groups activity can lead to the appearance (or increase the number) of photons with the energy of $\sim 6.67$ $\mathrm{eV}(\lambda \sim 185.8 \mathrm{~nm})$. They can be found by using the sensitive far-UV photodetectors. The detection of the ultra-weak UV emission will not be very surprising, because its availability in many biological systems is already long known [76]. 
The examples of some compounds with proven inhibition of SARS-CoV-2 entry into host cells are given in Table 1. Their chemical structures mostly agree with our approach. Bromelain, luteolin, and TGG (Table 1, compounds 11, 12, and 13) contain primarily the $\mathrm{OH}$ groups which define specific antiviral and some other biological properties of these compounds. The well-known vitamin $\mathrm{C}$ (ascorbic acid) mainly consists of the $\mathrm{OH}$ groups too (Table 1, compound 5) and has great promise in therapy for COVID-19, influenza, and some other diseases [77]. The described approach can also be effective against human immunodeficiency viruses, influenza viruses, and possibly other enveloped viruses. Further studies will provide a better understanding of the proposed mechanism and may lead to novel therapeutic findings against viral infections.

\section{Acknowledgement}

The author thanks Professor Gerald H. Pollack for the creative discussions of water-surface interactions.

Funding: No specific funding was received for this work.

Disclosures: Author declares no relationship with industry or other relevant entities that might pose a conflict of interest in connection with the submitted manuscript.

\section{References}

1. Walls AC, Park YJ, Tortorici MA, Wall A, McGuire AT, Veesler D. Structure, Function, and Antigenicity of the SARS-CoV-2 Spike Glycoprotein. Cell. 2020;181(2):281-292.e6. doi:10.1016/j.cell.2020.02.058.

2. Henderson R, Edwards RJ, Mansouri K, et al. Controlling the SARS-CoV-2 spike glycoprotein conformation. Nat Struct Mol Biol. 2020;10.1038/s41594-020-0479-4. doi:10.1038/s41594-020-0479-4.

3. Shang J, Wan Y, Luo C, et al. Cell entry mechanisms of SARS-CoV-2. Proc Natl Acad Sci U S A. 2020;117(21):11727-11734. doi:10.1073/pnas.2003138117.

4. Koehler M, Delguste M, Sieben C, Gillet L, Alsteens D. Initial Step of Virus Entry: Virion Binding to Cell-Surface Glycans. Annu Rev Virol. 2020;7(1):143-165. doi: 10.1146/annurev-virology-122019-070025. 
5. Hanke L, Vidakovics PL, Sheward DJ et al. An alpaca nanobody neutralizes SARS-CoV-2 by blocking receptor interaction. Nat Commun. 2020;11, 4420. https://doi.org/10.1038/s41467-020-18174-5.

6. Chen D, Oezguen N, Urvil P, et al. Regulation of protein-ligand binding affinity by hydrogen bond pairing. Science Advances. 2016;2(3):e1501240. doi: 10.1126/sciadv.1501240.

7. Raman R, Tharakaraman K, Sasisekharan V, Sasisekharan R. Glycan-protein interactions in viral pathogenesis. Curr Opin Struct Biol. 2016;40:153-162.

doi: 10.1016/j.sbi.2016.10.003.

8. Moore BE. Survival of human immunodeficiency virus (HIV), HIV-infected lymphocytes, and poliovirus in water. Appl Environ Microbiol. 1993;59(5):1437-1443. doi:10.1128/AEM.59.5.1437-1443.1993.

9. Gundy PM, Gerba CP \& Pepper IL. Survival of Coronaviruses in Water and Wastewater. Food Environ Virol. 2009; 1, 10. https://doi.org/10.1007/s12560-008-9001-6.

10. Pinon A, Vialette M. Survival of Viruses in Water. Intervirology. 2018;61(5):214-222. doi: 10.1159/000484899.

11. La Rosa G, Bonadonna L, Lucentini L, Kenmoe S and Suffredini E. Coronavirus in water environments: Occurrence, persistence, and concentration methods - A scoping review. Water Research. 2020; 179:115899.

12. Yang W, Marr LC. Mechanisms by which ambient humidity may affect viruses in aerosols. Appl Environ Microbiol. 2012;78(19):6781-8.

doi: 10.1128/AEM.01658-12.

13. Dbouk T, Drikakis D. Weather impact on airborne coronavirus survival. Physics of Fluids, 2020; 32 (9): 093312. doi: 10.1063/5.0024272.

14. Wu Y. et al. Effects of temperature and humidity on the daily new cases and new deaths of COVID-19 in 166 countries. Sci Total Environ. 2020; 10;729:139051. doi: 10.1016/j.scitotenv.2020.139051.

15. Poirier C, Luo W, Majumder MS at el. The Role of Environmental Factors on Transmission Rates of the COVID-19 Outbreak: An Initial Assessment in Two Spatial Scales. (March 9, 2020). Available at SSRN: http://dx.doi.org/10.2139/ssrn.3552677. 
16. Sale CS. Humidification to reduce respiratory illnesses in nursery school children. South Med J. 1972;65(7):882-5. doi: 10.1097/00007611-197207000-00024.

17. Barreca AI, Shimshack JP. Absolute humidity, temperature, and influenza mortality: 30 years of county-level evidence from the United States. Am J Epidemiol. 2012;176 Suppl 7:S114-22. doi: 10.1093/aje/kws259.

18. Kudo E, Song E, Yockey L, at el. Low ambient humidity impairs barrier function and innate resistance against influenza infection. PNAS 2019:116 (22) 10905-10910; https://doi.org/10.1073/pnas.1902840116.

19. Moriyama M, Hugentobler WJ, Iwasaki A. Seasonality of Respiratory Viral Infections. Annual Review of Virology 2020:7:1, 83-101 https://doi.org/10.1146/annurev-virology012420-022445.

20. Reiman JM, Das B, Sindberg GM, et al. Humidity as a non-pharmaceutical intervention for influenza A. PLoS One 2018;13(9):e0204337.

doi: 10.1371/journal.pone.0204337.

21. Dhar P, McAuley J. The Role of the Cell Surface Mucin MUC1 as a Barrier to Infection and Regulator of Inflammation. Front Cell Infect Microbiol 2019: 24;9:117. doi: 10.3389/fcimb.2019.00117.

22. Wheeler KM, Cárcamo-Oyarce G, Turner BS et al. Mucin glycans attenuate the virulence of Pseudomonas aeruginosa in infection. Nat Microbiol 2019;4: 2146-2154. https://doi.org/10.1038/s41564-019-0581-8.

23. Kifer D, Bugada D, Villar-Garcia J, Gudelj I, Menni C. et al. Effects of environmental factors on severity and mortality of COVID-19. medRxiv preprint doi: https://doi.org/10.1101/2020.07.11.20147157.

24. Watanabe Y, Bowden TA, Wilson IA, Crispin M. Exploitation of glycosylation in enveloped virus pathobiology. Biochim Biophys Acta Gen Subj 2019;1863(10):1480-1497. doi: 10.1016/j.bbagen.2019.05.012.

25. Bagdonaite I, Wandall HH. Global aspects of viral glycosylation. Glycobiology 2018;28(7):443-467. doi: 10.1093/glycob/cwy021.

26. Varki A. Biological roles of glycans. Glycobiology 2017;27(1):3-49. doi:10.1093/glycob/cww086. 
27. Espinosa-Marzal RM, Fontani G, Reusch FB, Roba M, Spencer ND, Crockett R. Sugars communicate through water: oriented glycans induce water structuring. Biophys $J$ 2013;104(12):2686-94. doi: 10.1016/j.bpj.2013.05.017.

28. Shajahan A., Heiss C., Ishihara M. et al. Glycomic and glycoproteomic analysis of glycoproteins - a tutorial. Anal Bioanal Chem 2017;409:4483-4505. https://doi.org/10.1007/s00216-017-0406-7.

29. Abeyratne-Perera HK, Chandran PL. Mannose Surfaces Exhibit Self-Latching, Water Structuring, and Resilience to Chaotropes: Implications for Pathogen Virulence. Langmuir 2017;33(36):9178-9189. doi: 10.1021/acs.langmuir.7b01006.

30. Heyden M, Bründermann E, Heugen U, Niehues G, Leitner DM, Havenith M. Long-range influence of carbohydrates on the solvation dynamics of water - answers from terahertz absorption measurements and molecular modeling simulations. J Am Chem Soc 2008;130(17):5773-9. doi: 10.1021/ja0781083.

31. Kanduč M, Schlaich A, Schneck E, and Netz RR. Water-Mediated Interactions between Hydrophilic and Hydrophobic Surfaces. Langmuir 2016;32 (35), 8767-8782. doi: 10.1021/acs.langmuir.6b01727.

32. Pollack, G.H. (2013). The fourth phase of water: Beyond Solid, Liquid, and Vapor. Seattle, WA: Ebner and Sons.

33. Hwang SG, Hong JK, Sharma A, Pollack GH, Bahng G. Exclusion zone and heterogeneous water structure at ambient temperature. PLOS ONE 2018;13:e0195057 doi: 10.1371/journal.pone.0195057.

34. Ebbinghaus S, Meister K, Born B. et al. Antifreeze glycoprotein activity correlates with long-range protein-water dynamics. J Am Chem Soc 2010 Sep 8;132(35):12210-1. doi: 10.1021/ja1051632.

35. Meister K, Ebbinghaus S, Xu Y. et al. Long-range protein-water dynamics in hyperactive insect antifreeze proteins. PNAS 2013;110 (5):1617-1622. https://doi.org/10.1073/pnas.1214911110.

36. Urbanczyk M, Gora J, Latajka R, Sewald N. Antifreeze glycopeptides: from structure and activity studies to current approaches in chemical synthesis. AMINO ACIDS 2017;49(2):209-22. https://doi.org/10.1007/s00726-016-2368-z

37. Ball P. Water as an active constituent in cell biology. Chem Rev 2008;108(1):74-108. 
doi: $10.1021 /$ cr068037a.

38. Ball P. Water is an active matrix of life for cell and molecular biology. Proc Natl Acad Sci U S A 2017;114(51):13327-13335. doi: 0.1073/pnas.1703781114.

39. Farhadi A. Non-Chemical Distant Cellular Interactions as a potential confounder of cell biology experiments. Front. Physiol 2014;5:405-407. doi: 10.3389/fphys. 2014.00405.

40. Heßling M, Hönes K, Vatter P, Lingenfelder C. Ultraviolet irradiation doses for coronavirus inactivation- review and analysis of coronavirus photoinactivation studies. GMS Hyg Infect Control 2020;15: Doc08. doi: 10.3205/dgkh000343.

41. Buonanno, M, Welch, D, Shuryak, I. et al. Far-UVC light (222 nm) efficiently and safely inactivates airborne human coronaviruses. Sci Rep 2020;10:10285. https://doi.org/10.1038/s41598-020-67211-2.

42. Szeto W, Yam WC, Huang H, Leung DYC. The efficacy of vacuum-ultraviolet light disinfection of some common environmental pathogens. BMC Infect Dis 2020;20(1):127. doi:10.1186/s12879-020-4847-9.

43. Beck SE, Rodriguez RA, Hawkins MA, Hargy TM, Larason TC, Linden KG. Comparison of UV-Induced Inactivation and RNA Damage in MS2 Phage across the Germicidal UV Spectrum. Appl Environ Microbiol 2015;82(5):1468-1474. doi:10.1128/AEM.02773-15.

44. Furatian L, Mohseni M. Temperature dependence of $185 \mathrm{~nm}$ photochemical water treatment - The photolysis of water. Journal of Photochemistry and Photobiology A: Chemistry 2018;356:364-369.

45. Liu Y and Ogden K. Benefits of high energy UV $185 \mathrm{~nm}$ light to inactivate bacteria. Water Sci Technol 2010;62(12):2776-2782. doi: 10.2166/wst.2010.200.

46. McGivney E, Carlsson M, Gustafsson JP, Gorokhova E. Effects of UV-C and Vacuum-UV TiO2 Advanced Oxidation Processes on the Acute Mortality of Microalgae. Photochem Photobiol 2015;91(5):1142-1149. doi:10.1111/php.12473.

47. Peters RD. Using Spectral Measurements to Differentiate Between Aqueous $\mathrm{NaCl}$ and Aqueous KCl in Dual-Salt Solutions [M.Sc. Thesis], 2016; Corpus ID: 99714502. https://harvest.usask.ca/handle/10388/7489.

48. Le Brun E, Arluison V, Wien F. Application of Synchrotron Radiation Circular Dichroism for RNA Structural Analysis. In: Arluison V, Wien F (eds). Methods in Molecular Biology 2020; vol 2113. Humana, New York, NY. 
49. Gekko K. Synchrotron-radiation vacuum-ultraviolet circular dichroism spectroscopy in structural biology: an overview. Biophys Physicobiol 2019;16:41-58. doi:10.2142/biophysico.16.0_41.

50. Riazance JH, Baase WA, Johnson WC Jr, Hall K, Cruz P, Tinoco I Jr. Evidence for Z-form RNA by vacuum UV circular dichroism. Nucleic Acids Res 1985;13(13):4983-4989. doi:10.1093/nar/13.13.4983.

51. Johnson KH, Gray DM, Morris PA, Sutherland JC. A $\cdot \mathrm{U}$ and $\mathrm{G} \cdot \mathrm{C}$ base pairs in synthetic RNAS have characteristic vacuum UV CD bands. Biopolymers 1990;29(2):325-333. doi:10.1002/bip.360290205. https://onlinelibrary.wiley.com/doi/abs/10.1002/bip.360290205

52. Johnson KH, Durland RH, Hogan ME. The vacuum UV CD spectra of G.G.C triplexes. Nucleic Acids Res 1992;20(15):3859-3864. doi:10.1093/nar/20.15.3859.

53. Beck SE, Rodriguez RA, Linden KG, et al. Wavelength dependent UV inactivation and DNA damage of adenovirus as measured by cell culture infectivity and long-range quantitative PCR. Environ Sci Technol 2014;48:591-598. doi:10.1021/es403850b.

54. Uchiho Y, Goto Y, Kamahori M, et al. Far-ultraviolet absorbance detection of sugars and peptides by high-performance liquid chromatography. J Chromatogr A 2015;1424:86-91. doi:10.1016/j.chroma.2015.11.006.

55. Ham JS, Platt JR. Far UV spectra of peptides. J Chem. Phys 1952;20:335-336. https://doi.org/10.1063/1.1700403.

56. Bruening EM, Schauss J, Siebert T, Fingerhut BP, and Elsaesser T. Vibrational Dynamics and Couplings of the Hydrated RNA Backbone: A Two-Dimensional Infrared Study. J. Phys. Chem. Lett 2018;9(3):583-587. doi:10.1021/acs.jpclett.7b03314.

57. Berg RW. Investigation of L(+)-Ascorbic Acid with Raman Spectroscopy in Visible and UV Light. Applied Spectroscopy Reviews 2015;50(3):193-239. https://doi.org/10.1080/05704928.2014.952431.

58. Khazraji AC and Robert S. Interaction Effects between Cellulose and Water in Nanocrystalline and Amorphous Regions: A Novel Approach Using Molecular Modeling. Journal of Nanomaterials 2013; 44. https://doi.org/10.1155/2013/409676.

59. Yi L, Li Z, Yuan K, et al. Small molecules blocking the entry of severe acute respiratory syndrome coronavirus into host cells. J Virol 2004;78:11334-11339. https://doi.org/10.1128/jvi.78.20.11334-11339.2004. 
60. Colunga Biancatelli RML, Berrill M, Catravas JD, Marik PE. Quercetin and Vitamin C: An Experimental, Synergistic Therapy for the Prevention and Treatment of SARS-CoV-2 Related Disease (COVID-19). Front Immunol 2020;11:1451 doi:10.3389/fimmu.2020.01451.

61. Hoffmann M, Mösbauer K, Hofmann-Winkler H, et al. Chloroquine does not inhibit infection of human lung cells with SARS-CoV-2 [published online ahead of print, $2020 \mathrm{Jul}$ 22]. Nature 2020;10.1038/s41586-020-2575-3. doi:10.1038/s41586-020-2575-3.

62. Ho TY, Wu SL, Chen JC, et al. Emodin blocks the SARS coronavirus spike protein and angiotensin-converting enzyme 2 interaction. Antivir Res 2007;74:92-101. https://doi.org/10.1016/j.antiviral.2006.04.014.

63. Dong X, Fu J, Yin X, et al. Emodin: A Review of its Pharmacology, Toxicity and Pharmacokinetics. Phytother Res 2016;30(8):1207-1218. doi:10.1002/ptr.5631.

64. Yoon JJ, Toots M, Lee S, et al. Orally Efficacious Broad-Spectrum Ribonucleoside Analog Inhibitor of Influenza and Respiratory Syncytial Viruses. Antimicrob Agents Chemother 2018;62(8):e00766-18. doi:10.1128/AAC.00766-18.

65. Sheahan TP, Sims AC, Zhou S, et al. An orally bioavailable broad-spectrum antiviral inhibits SARS-CoV-2 in human airway epithelial cell cultures and multiple coronaviruses in mice. Sci Transl Med 2020;12(541):eabb5883. doi:10.1126/scitranslmed.abb5883.

66. Sagar S, Rathinavel AK, Lutz WE, et al. 2020. Bromelain Inhibits SARS-CoV-2 Infection in VeroE6 Cells. bioRxiv doi: https://doi.org/10.1101/2020.09.16.297366

67. Pagnotta SE, McLain SE, Soper AK, Bruni F, Ricci MA. Water and trehalose: how much do they interact with each other? J Phys Chem B 2010;114(14):4904-8. doi: 10.1021/jp911940h

68. Lerbret A, Affouard F, Bordat P, Hédoux A, Guinet Y, Descamps M. Slowing down of water dynamics in disaccharide aqueous solutions. Journal of Non-Crystalline Solids 2011;357(2):695-699. https://doi.org/10.1016/j.jnoncrysol.2010.05.092.

69. Olsson C, Genheden S, García Sakai V, Swenson J. Mechanism of Trehalose-Induced Protein Stabilization from Neutron Scattering and Modeling. J Phys Chem B. 2019;123(17):36793687. doi: 10.1021/acs.jpcb.9b01856.

70. Olsson C, Zangana R, and Swenson J. Stabilization of proteins embedded in sugars and water as studied by dielectric spectroscopy. Phys. Chem. Chem. Phys., 2020;22(37): 21197-21207. https://doi.org/10.1039/D0CP03281F. 
71. Ahmed AI, Yeh Y, Osuga DT and Feeney RE. Antifreeze glycoproteins from Antarctic fish. Inactivation by borate. J. Biol. Chem 1976; 251(10):3033-3036. http://www.jbc.org/content/251/10/3033.

72. Peltier R, Brimble MA, Wojnar JM, Williams DE, Evans CW and L. DeVries AL. Synthesis and antifreeze activity of fish antifreeze glycoproteins and their analogues. Chem. Sci 2010;1(5): 538-551 https://doi.org/10.1039/c0sc00194e.

73. Weng L, Stott SL, Toner M. Molecular Dynamics at the Interface between Ice and Poly(vinyl alcohol) and Ice Recrystallization Inhibition. Langmuir 2018;34(17):5116-5123. doi: 10.1021/acs.langmuir.7b03243.

74. Bleszynski M, Reil M, Kumosa M. Hydroxyl Group Separation Distances in Anti-Freeze Compounds and Their Effects on Ice Nucleation. Int. J. Mol. Sci 2020;21(22):8488 doi: 10.3390/ijms21228488.

75. Lupi L, Comez L, Paolantoni M. et al. Hydration and aggregation in mono- and disaccharide aqueous solutions by gigahertz-to-terahertz light scattering and molecular dynamics simulations. J Phys Chem B. 2012;116(51):14760-7. doi: 10.1021/jp3079869.

76. Cifra M, Fields JZ, Farhadi A. Electromagnetic cellular interactions. Prog Biophys Mol Biol. 2011;105(3):223-46. doi: 10.1016/j.pbiomolbio.2010.07.003.

77. Holford P, Carr AC, Jovic TH et.al. Vitamin C-An Adjunctive Therapy for Respiratory Infection, Sepsis and COVID-19. Nutrients. 2020; 12(12):3760.

https://doi.org/10.3390/nu12123760.1. 